\title{
10 Health and social outcomes of housing policies to alleviate fuel poverty
}

Author: Professor Wouter Poortinga, Welsh School of Architecture, Cardiff University, Bute Building, King Edward VII Avenue, Cardiff, CF10 3NB, Wales, United Kingdom

\subsection{Introduction}

\subsubsection{Background}

It is now well-established that fuel poverty can have a profound impact on people their wellbeing and quality of life. Fuel poverty is an inability to attain an adequate level of essential energy services at a reasonable cost (Boardman, 1991), and is typically manifest in a lack of affordable warmth at home (Simcock, Walker and Day, 2016). The consequences of fuel poverty have therefore usually been explored in the context of cold homes and health (Marmot Review Team et al., 2011). However, while cold homes are an essential component for understanding the relationships between fuel poverty and health (Hills, 2012), they are only one aspect of a complex and multifaceted phenomenon (Baker, Mould and Restrick, 2018). Fuel poverty is produced through a complex interplay of low incomes, energy inefficient housing, and high costs of fuel (Hills, 2012), with several feedback loops in which vulnerable households may become trapped (Baker et al., 2018). In addition, the negative outcomes of living in fuel poverty are not restricted to poor physical health. Fuel poverty has a profound impact on people's general wellbeing and quality of life, as well as their capability to function normally and to live a decent social life (Day, Walker and Simcock, 2016). Policies to address fuel poverty in the UK have typically focused on income support and improving the energy-efficiency of housing. The UK has some of the oldest housing stock in the UK, with nearly 38\% of its homes dating from before 1946 (Nicol et al., 2016). Improving the quality of housing is therefore likely to bring multiple benefits in term of the living conditions of low-income households and to help lift them out of fuel poverty by removing one of its main contributing factors.

\subsubsection{Overview of the chapter}

This chapter provides an overview of the benefits of policies to alleviate fuel poverty, and in particular those that improve the quality of housing. It takes the perspective that, in order to best understand how to improve the lives of those in energy policy, mental and social wellbeing need to be considered together with physical health. The chapter will do this by first reviewing the quantitative and qualitative literature on the consequences of living in fuel poverty and cold homes. This provides a foundation for understanding fuel poverty, and is used to construct a conceptual model of how fuel poverty may impact on people's health and wellbeing, as well as the possible mediating pathways. Subsequently, the chapter presents an overview of current fuel poverty policies in the UK, together with a discussion of the international evidence on their effectiveness. This part of the chapter will present a summary of a selected number of studies that show the health and social outcomes of income support and home energy-efficiency improvements, respectively. After establishing that energy-efficiency policies produce more sustained benefits than income support, the chapter discusses whether the way housing policies are delivered makes a difference. This is done by reviewing recent research evidence from Wales that evaluated a range of fuel poverty and housing quality policies. The chapter is concluded by discussing the policy implications of the findings.

\subsection{Consequences of living in fuel poverty and cold homes}

\subsubsection{Physical health}

Fuel poverty and living in cold homes are linked to a range of adverse outcomes, and have been shown to be particularly detrimental to cardio-respiratory health through the effects of low temperatures on the blood (Woodhouse, Khaw and Plummer, 1993; Crawford, 2003) and immune function (Howieson, 2005). Low temperatures impair respiratory function and put strain on the cardiovascular system, and the longer the exposure to low temperatures, the greater the risk of developing severe cardio-respiratory conditions (Public Health England, 2014). Low indoor temperatures also encourage the development of damp and mould within the home, in particular in a wet climate, and this is a recognised risk factor in respiratory disease in both adults and children (Gunnbjörnsdóttir et al., 2006; Fisk, Lei-Gomez and Mendell, 2007). The central role of housing quality in the development of cardio-respiratory conditions is further evidenced by excess winter mortality being three times higher in cold homes as compared to warm homes (Wilkinson et al., 2001) and the excess being largely attributable to circulatory and respiratory conditions (ONS, 2016).

Due to the health consequences associated with exposure to low indoor temperatures, minimum thresholds have been incorporated into the measurement of fuel poverty and recommended to particular population groups in order to protect their health in cold weather (World Health Organization, 1985; Boardman, 2013; Public Health England, 2014; Jevons et al., 2016). Jevons and colleagues (2016) suggests that a temperature of $18^{\circ} \mathrm{C}$ throughout the day and overnight is important to protect the health of those aged 65 and over and for those with pre-existing medical conditions, but may be less important for healthy people as long as they are active and wearing appropriate clothing. Temperatures are however often 
well below this thresholds in low-income households, in particular in the bedroom during the night (Oreszczyn et al., 2006), and show wide variations that reflect poor efficiency of heating systems and fabric (ibid).

\subsubsection{Mental and social wellbeing}

Living in cold homes and fuel poverty have also been linked to poor mental health, with common mental disorders being more common among those who experience fuel-related poverty and live in cold and mouldy homes, even after adjusting for potential financial and socio-economic factors (Harris et al., 2010). It is difficult to establish causal effects in this realm, as poverty, poor housing, and poor mental health are closely interlinked. Vulnerable groups are more likely to have common mental disorders and are also more likely to live in poor quality housing. Nevertheless, there is growing evidence to suggest that poor housing and living in cold conditions are important contributing factors. Several routes have been identified through which prolonged exposure to low temperatures can affect mental health and wellbeing, illustrating the importance of psycho-social factors when considering the consequences of living in fuel poverty (Gilbertson, Grimsley and Green, 2012; Thomson and Thomas, 2015). The literature suggests that mental wellbeing is affected through factors associated with thermal comfort and the affordability of running a household (Grey, Jiang, et al., 2017), in addition to a more direct pathway of poor housing conditions to cardio-respiratory health. Figure 1 is a conceptual model that illustrates how the different pathways are potentially interlinked.

Continued experiences of thermal discomfort and worries about damp and mould may contribute to poor mental health and depression (Evans, 2003; Shenassa et al., 2007). Stigma associated with fuel poverty can exacerbate social isolation by making people reluctant to invite friends into their cold home (Middlemiss and Gillard, 2015; Grey, Jiang, et al., 2017). In particular, older and those living on their own have been found to be at risk of isolation (Petticrew et al., 2013). Furthermore, those living in cold homes have been found to participate in fewer social activities outside of the home (Cotter et al., 2012). Those living in cold homes are less likely to leave the house for fear of being out in the cold, but may also be prevented from doing so due to budget constraints (Marmot Review Team et al., 2011). This may be further compounded by poor mobility as a result of old age or diability (Age UK, 2014). Spatial shrink, where fewer rooms are heated and occupied in the winter months in order to save on fuel costs, may strain household relationships because less usable space provides fewer opportunities for privacy and personal space (Gilbertson et al., 2006). This could have a particular negative impact on adolescents due to them not being able to spend enough time on their own (Kwak, 2003). This may not only lead to poor educational outcomes but can also increase adolescents' vulnerability to anti-social behaviour and mental illness (Wells et al., 2005; Barnes, Butt and Tomaszewski, 2010). The mental and physical health consequences of low indoor temperatures, such as asthma and other respiratory illnesses, could also contribute to days lost from school and affect educational attainment (Somerville et al., 2000; Howden-Chapman et al., 2008)

Low incomes and high spending on fuel to keep the home warm brings along financial stress and reduced choice, which can have severe implication for someone's mental wellbeing (Marmot Review Team et al., 2011; Gilbertson, Grimsley and Green, 2012). Those affected by fuel poverty often adopt different coping strategies that allow them to stay warm in poor financial circumstances (Gibbons and Singler, 2008). They may reduce fuel usage through rationing (Harrington et al., 2005), for example by turning down the thermostat and reducing consumption of hot water (Brunner, Spitzer and Christanell, 2012) or by disconnecting themselves from pre-payment meters where they are present (Doble, 2010). Households may also choose to keep their home warm, but then they need to reduce their expenditure on other essential items, such as food, clothing and transport (Bhattacharya et al., 2003; Beatty, Blow and Crossley, 2014). Fuel poor households who trade warmth for other essentials primarily have been found to restrict their spending on food in periods of unusually cold weather, with older fuel poor households being affected to greater extent (ibid). This phenomenon is now commonly known as the 'heat-or-eat' dilemma. Changes in dietary choices, both in terms of quantity and quality of foods purchased and consumed (Gibbons and Singler, 2008; Anderson, White and Finney, 2012) risks malnutrition, and as such may widen health inequalities between those living in cold homes and those living in warm homes (Lee, Ralston and Truby, 2011). Continued spending on heating can help evade some of the health consequences but the financial stress associated with attempting to keep the home warm may affect mental health and can lead to the build-up of debt (Gilbertson et al., 2006). Qualitative research has shown that cold homes and concerns about household finances are experiences as stressful and depressing (Harrington et al., 2005; Anderson, White and Finney, 2012; Grey, SchmiederGaite, et al., 2017).

\subsection{Health and social outcomes of different policies to alleviate fuel poverty}

\subsubsection{Fuel poverty policies in the UK}

The prevalence of fuel poverty has been persistent both in the UK and across parts of Europe (Thomson and Snell, 2013). This is in part due to a slow political acceptance of the issue (Boardman, 2013), but also to a lack of consensus on how fuel poverty should be defined and thus addressed (Baker, Mould and Restrick, 2018). In 1991, Brenda Boardman suggested the first quantitative definition of fuel poverty of households (i.e. being unable to obtain an adequate level of energy services, particularly warmth, for 10 per cent of their income), which is now commonly known as the 10 per cent indicator. This threshhold was set at twice the level of the median spend on fuel to heat the home, which at that time was 
around $5 \%$ of household income. It was only around a decade later that the definition became part of government policy with the development of the Warm Homes and Conservation Act of 2000, which required the UK government to construct and implement a policy that would outline plans to eliminate fuel poverty within 15 years (Defra \& DTI, 2001). Fuel poverty however increased dramatically after the introduction of the act, mainly as a result of rapidly rising energy prices in the early 2000s; clearly illustrating a main drawback of the original 10 per cent indicator being sensitive to fuel price changes. This prompted the development of a Low Income High Costs indicator that defines fuel poverty as having "required fuel costs that are above the median level" and where the spend leads to "a residual income below the official poverty line" (Hills, 2012). While the revised measure has its own shortcomings (Moore, 2012; Baker, Mould and Restrick, 2018), the changes mean that the definition no longer includes households who are able to afford higher fuel costs and distinguishes fuel poverty from general income poverty.

Several policies have been adopted in England to address fuel poverty, consisting of income support measures, fuel price support, and home energy-efficiency programmes (Sunderland and Croft, 2011). These policies are designed to address its underlying factors, namely low incomes, high fuel prices and energy inefficient homes, respectively. The greatest part of the strategy involves direct payments to households that are at risk of fuel poverty, through winter fuel payments, cold weather payments and benefits entitlement checks (ibid). Winter fuel payments (WFPs) are labelled but unconditional income transfers to households containing an older person above the female state pension age. Cold Weather Payments (CWPs) are made to low-income households when outdoor temperatures are at or below zero degrees Celsius for at least seven consecutive day. The Warm Home Discount (WHD) is a mandatory social price support measure that was introduced in addition to the WFP, and replaced social tariffs that were available to households vulnerable to fuel poverty. The WHD has more restrictive eligibility criteria than the WFP, but similarly tends to favour those of retirement age (Snell, Bevan and Thomson, 2015). While WFPs and price supports may help to plug the income gap underlying fuel poverty, energy-efficiency measures are often seen as a more long-term solution to fuel poverty. Home energy-efficiency improvement measures in England have been funded through a number of schemes and programmes, including Warm Front and supplier obligations to reduce carbon emissions. Fuel poverty is a devolved issue, and each UK country has its own definition, targets and policies (Welsh Assembly Government, 2010; DECC, 2015; Scottish Government, 2018). For example, the Welsh Government maintained the 10 per cent indicator of fuel poverty after the Hills review, and the Scottish Government updated their measure in the 2018 fuel poverty strategy combining elements of the two existing indicators (Scottish Government, 2018). The devolved Governments have organised their own targeted and area-based energy-efficiency programmes in addition to the national WFP and WHD measures. The different Welsh schemes and their health and social impacts are discussed in more detail in section 1.4.

\subsubsection{Health and social outcomes of income support measures}

Research shows that energy-efficiency measures are not only a more sustainable and cost effective way of tackling fuel poverty (Sunderland and Croft, 2011), but have a wider range of health and social benefits as well (Liddell and Morris, 2010). While the labelling of WFPs as a benefit to help with energy costs prompts households to use it in that way (Beatty et al., 2011), there is little evidence of substantially warmer homes producing benefits in terms of health and wellbeing (Angelini et al., 2018). Research from the US shows that receipt of home energy assistance is associated with fewer acute hospital admission and with lowered risks associated with undernutrition of young children living in low-income households (Frank et al., 2006). In addition, indications are that the association between outdoor cold and mortality has weakened after the introduction of WFPs in England, but these changes are relatively modest and may in part reflect other changes that have occurred over the same period (Iparraguirre, 2015; Armstrong et al., 2018). Overall the WFP can be considered an inefficient instrument for alleviating fuel poverty because, as a non-means tested benefit, it is handed to many households who may not need it. WFP also does not reach households that do not have a member of pensionable age, including those who are most at risk of fuel poverty such as single-parent households. No studies have been conducted on possible health and social benefits associated with the Warm Homes Discount and/or Cold Weather Payments.

\subsubsection{Health and social outcomes of energy-efficiency improvements}

More evidence is available showing the health and social benefits of fuel poverty measures that involve home energyefficiency improvements. A health impact evaluation of the Warm Front scheme found major changes following the intervention (Green and Gilbertson, 2008b), although the study did not directly report quantitative data on changes in physical health (Thomson et al., 2013). The scheme helped to increase the mean indoor temperature by nearly $2^{\circ} \mathrm{C}$ across the whole house, leading to more usable space within the home and a majority of the recipients feeling thermally comfortable throughout (Hong et al., 2009). Perhaps most importantly, the research highlighted the psycho-social benefits of housing investments (Gilbertson, Grimsley and Green, 2012), with quantitative and qualitative reports of improved thermal comfort, greater living space, and better family relations, as well as reduced anxiety because of more reliable heat (Gilbertson et al., 2006). A before-and-after household survey found that those receiving heating and insulation measures were less likely to report depression and housing-related problems such as draft or condensation (Gilbertson, Grimsley and Green, 2012). Reductions in fuel poverty and financial stress were most strongly associated with improved mental health (ibid). The study therefore concluded that a reduction in perceived financial strain is one of the main routes to 
mental health gains, and that the scheme was particularly successful in improving living conditions of low income household (Oreszczyn et al., 2006).

The wider literature evaluating affordable warmth and energy-efficiency interventions have produced conflicting findings in terms of general and respiratory health (Thomson et al., 2013). The studies that reported greatest health impacts had the strongest research design but also provided the interventions according to need. This suggests that potential health gains can in particular be expected where interventions target those with pre-existing conditions (Barton et al., 2007; Howden-Chapman et al., 2007; Shortt and Rugkåsa, 2007; Osman et al., 2010). The Housing, Insulation and Heath Study (which targeted households in low-income communities with at least one occupant with a chronic respiratory condition) found that retrofitted insulation produced significantly warmer homes with fewer damp-related problems and reduced spending on heating (Howden-Chapman et al., 2007). This resulted in better self-reported general and respiratory health, although no evidence was found for fewer hospital admissions and visits to the family doctor. The study further found that the relatively modest investments led to adults having fewer sick days off work and children having fewer days off school. In an uncontrolled intervention study, Somerville et al. (2000) found that the installation of a central heating system can help alleviate respiratory symptoms among children with diagnosed asthma through better heated bedrooms, which led to fewer days off school for asthma-related reasons. This was mirrored by a study in which a ventilation and heating intervention led to improved asthma-specific quality of life among children and, although the effects of the two interventions were not separated when analysing the results (Woodfine et al., 2011). Osman and colleagues (2010) similarly found that adult patients diagnosed with chronic obstructive pulmonary disease (COPD) experienced significant improvements in respiratory symptoms following energy-efficiency improvements. The latter study may however been compromised by contamination in their randomisation.

There is further evidence that housing interventions may improve various aspects of mental health and wellbeing of recipients (Thomson et al., 2013), with a number of studies producing mixed and/or inconclusive results (Barton et al., 2007; Braubach, Heinen and Dame, 2008). A recent review exploring associations of improved domestic energyefficiency with mental wellbeing concluded that the available evidence is generally of good quality but that its base is relatively sparse (Liddell and Guiney, 2015). Studies on mental health have used a relatively limited number of outcomes, including subscales relating to the short form health survey (SF-36 and SF-12) and other widely-used measures. Again, greater changes were found for interventions that were offered according to need than for those that were more generic and/or area-based (Thomson et al., 2013). For example, Barton et al (2007) found no improvements in mental health following energy-efficiency upgrades on social housing compared to the control group. Similarly, an evaluation of the Scottish Central Heating Programme, which provided energy-efficiency improvements to low-income households in the private and social-rented sector (Platt et al., 2007) found that, while it significantly reduced condensation, damp and cold in recipients' homes, there is little evidence of it having clear and systematic impact on residents' health and heath service use. In particular the intervention was not associated with the vitality, social functioning, role-emotional and mental health subscales of the SF-36. In contrast, studies that specifically targeted those with existing health conditions did find changes in mental health. For example Howden-Chapman et al. (2007) reported statistically significant improvements in social and mental wellbeing following the intervention. The households in the study were identified as having inadequate warmth and were all at clinical risk of ill health before the intervention. Shortt and Rugkåsa (2007) provided a housing intervention to those with an increased risk of fuel poverty and ill health. The study saw a significant reduction in reported common mental disorders alongside greater thermal comfort and better control over heating.

The studies reported here have shown a range of secondary psycho-social benefits that may be conducive to better health, as already partly reported above. Even those that found no clear physical or mental health effects have reported consistent changes along the housing conditions, affordability and thermal comfort pathways (see Figure 1). A multitude of studies found improved housing conditions, higher indoor temperatures and lower humidity levels, and as a result improved thermal comfort and satisfaction (Howden-Chapman et al., 2007; Platt et al., 2007; Shortt and Rugkåsa, 2007; Braubach, Heinen and Dame, 2008; Green and Gilbertson, 2008a; Hong et al., 2009). These improvements have been linked to qualitative reports of enhanced feelings about the home, particularly as a safe haven and as providing emotional security and empowerment (Gilbertson et al., 2006), and increased enjoyment of the home (Harrington et al., 2005; Gilbertson et al., 2006; Bullen et al., 2008; Willand, Ridley and Maller, 2015), as well as reduced social isolation and greater use of space within the home (Gilbertson et al., 2006; Platt et al., 2007). There are also widespread reports that energy-efficiency improvements reduce spending on fuel, making it (Howden-Chapman et al., 2007; Shortt and Rugkåsa, 2007; Gilbertson, Grimsley and Green, 2012)

\subsubsection{Summary of evidence}

The balance of the available pool of evidence suggests that home energy-efficiency interventions deliver net benefits in in terms of physical and mental health, although the effects can be considered modest (Milner and Wilkinson, 2017). Thomson and colleagues (2013) concluded in their systematic review that schemes targeting households with inadequate warmth and pre-existing conditions are the most likely to produce health improvements, while area-based interventions targeting low-income households produce more conflicting results. The effects of housing-led neighbourhood renewal 
are also less clear (ibid). The evidence base for the effectiveness of housing improvements is however thin. The literature indicates the potential for longer term health impacts, but follow-up periods are generally short (i.e. less than one year), and there have been few studies that examine psycho-social pathways to health in more detail. In addition, only a handful of studies have attempted to link housing interventions with healthcare utilisation data as opposed to relying upon selfreports (Milner and Wilkinson, 2017).

In the next section we discuss a number of recently published studies that have evaluated different housing programmes in Wales, some of which were specifically aimed at alleviating fuel poverty. These studies used a multitude of methodologies, including community-based surveys (Grey, Jiang, et al., 2017; Poortinga et al., 2017), household monitoring (Poortinga, Jiang, et al., 2018), qualitative focus groups (Grey, Schmieder-Gaite, et al., 2017), and linkage of routinely collected health-service utilisation data (Morrison-Rees, 2016; Poortinga, Rodgers, et al., 2018). Together these studies shed further light on the health and social outcomes of different housing policies, and may be compared due to their geographical proximity

\subsection{Health and social outcomes of different housing programmes: Recent evidence from Wales}

\subsubsection{Housing programmes in Wales: Arbed, Nest and the WHQS}

In a bid to fulfil the aims of the 2010 Fuel Poverty Strategy for Wales, the Welsh Government developed the Warm Homes programme, which consists of a demand-led and a more general area-based scheme, to work alongside UK-wide fuel poverty policies (Welsh Assembly Government, 2010). Nest is the demand-led part of the Warm Homes programme, and offers free home energy-efficiency improvement to eligible households who own or privately rent an energyinefficient home and are in receipt of a means-tested benefit. Arbed (meaning 'save' in Welsh) is the area-based supplyled part of the Warm Homes programme, and has provided funding to improve the energy-efficiency of households living in deprived communities across Wales. Arbed was set up in 2009 and aimed to (1) reduce the number of households living in fuel poverty, (2) create jobs and regeneration in Wales and (3) combat climate change by reducing greenhouse gas emissions. The programme consisted of two phases. The first phase (Arbed 1) took place in 2010 and 2011. The second phase (Arbed 2) took place between 2012 and 2015 (Poortinga, Rodgers, et al., 2018). The third phase (Arbed 3) was ongoing at the time of writing, and was to be delivered between 2018 and 2021.

The Welsh Housing Quality Standard (WHQS) is not a fuel poverty programme, but requires all social landlords to improve their housing stock to an acceptable level (Welsh Assembly Government, 2008). This includes a minimum efficiency standard of SAP $65^{1}$. The standard aims to ensure that all socially rented homes in Wales are in a good state of repair, safe and secure, adequately heated, fuel efficient and well insulated. The WHQS can as Arbed be considered an area-based programme given that UK social housing tends to be concentrated within estates, but is a more substantial managed housing upgrade programme, and can as such be seen as housing-led neighbourhood renewal (cf. Thomson et al., 2013). The studies evaluating the standard followed a programme of housing improvements delivered by Carmarthenshire County Council. This involved a rolling programme of multiple internal and external upgrades that were suplied over an extended period (Rodgers, Bailey, Johnson, Poortinga, et al., 2018).

\subsubsection{Health and social outcomes of area-based, demand-led, and managed housing programmes}

A first group of studies evaluated the area-based supply-led Arbed and targeted demand-led Nest fuel poverty programmes. Grey, Jiang et al. (2017) examined the short-term health and psychosocial impacts of the Arbed programme through a controlled before-and-after community-based study. The study had a dedicated focus psych-social outcomes alongside physical and mental health, based on the conceptual model depicted in Figure 1). Data on the outcomes were collected in the heating season before and the heating season after the installation of the energy-efficiency measures, meaning that there was a relatively short follow up. The study found no evidence of physical and mental health improvements in the short term, but did find significant changes in terms of improved subjective wellbeing, living conditions and thermal satisfaction, and reduced reports of fuel poverty, financial difficulties, and social isolation. The study was accompanied by household monitoring at baseline and follow-up in a subset of the intervention and control households (Poortinga, Jiang, et al., 2018). It reported that the intervention raised the whole-house indoor air temperature by $0.84{ }^{\circ} \mathrm{C}$ relative to the control households, although greater changes were recorded in the evening and night, in particular in the bedroom, suggesting that the intervention affords a greater use of living space (cf. Gilbertson et al., 2006). The study further found substantially lower energy bills, meaning that the intervention made heating more affordable in addition to providing better living conditions that are conducive to good physical and mental health. Many of the findings were corroborated by the occupants themselves, who reported improvements in terms of wellbeing and quality of life, financial stress, thermal comfort, social interaction and indoor space usage (Grey, Schmieder-Gaite, et al., 2017). This group of studies are largely in line with the conclusions of Thomson and colleagues (2013) that area-based approaches

1 The Standard Assessment Procedure (SAP) is a methodology used by UK Governments to determine the energy performance of domestic dwellings. The SAP rating has a scale of 1 to 100 with higher numbers indicating lower running costs. 
that do not discriminate according to need may not necessarily produce or detect discernible health improvements, especially those that have limited follow-up periods. They did however find improvements in all psycho-social outcomes along the three pathways to physical and mental health (see Figure 1), showing that area-based interventions deliver widespread benefits even in an absence of clear direct health effects.

Two studies using data linkage show the effects of area-based programmes versus more targeted demand-led programmes. Poortinga, Rodgers et al. (2018) conducted a longitudinal analysis of residents who received energy-efficiency improvements in the first phase of the Arbed programme. The study obtained before and after health-service utilisation data for intervention and control populations, but did not find an intervention effect for emergency hospital admissions over an extended period of time. The findings of Poortinga, Rodgers et al. (2018) are in contrast to those of Morison-Rees (2006), who used similar data linkage methods to evaluate the demand-led Nest programme. The study recorded hospital admissions for both cardiovascular and respiratory conditions in the winter periods before and after households received home energy improvements. Significant decreases in health service use among people who had benefited from the Welsh Government Warm Homes Nest scheme (Welsh Government, 2017). These findings further confirm that demand-led programmes are more likely to be successful than area-based ones, and suggest that their benefits become apparent soon after measures have been taken.

A second set of studies followed the implementation of the WHQS in Carmarthenshire (Poortinga et al., 2017; Rodgers, Bailey, Johnson, Berridge, et al., 2018). Carmarthenshire County Council further developed the standard after a consultation with their tenants (Rodgers, Bailey, Johnson, Poortinga, et al., 2018). The resulting Carmarthenshire Homes Standard was subsequently delivered through a managed upgrade programme that took nearly 10 year to complete. This was done through a rolling programme of multiple interventions, allowing people to remain in their homes for the duration of the intervention. Rodgers, Bailey, Johnson, Berridge, et al., 2018 anonymously linked the intervention records to hospital admission data and GP practice data concerning primary care contacts and prescribed medications (Rodgers, Bailey, Johnson, Berridge, et al., 2018). The study found that emergency hospital admissions for cardiorespiratory conditions were considerably lower among residents who were living in upgraded homes as compared to those living in unupgraded homes. Reduced admissions were found for a number of interventions, but relevant to this chapter, wall insulation was associated with reduced emergency admissions for combined condition and for cardiovascular and respiratory conditions separately. These effects were found for respondents aged 60 years and over as well as for respondents of all ages. A parallel study followed the managed upgrade programme using five repeated cross-sectional surveys (Poortinga et al., 2017). The surveys were similarly linked to intervention records that were kept by the council, showing that a majority of the individual and cumulative housing measures were associated with improvements in several social (e.g. thermal comfort and household financed) and health (i.e. mental, respiratory and general health) outcomes (cf., Grey, Jiang et al., 2017). This included both loft and external wall insulation. However, in contrast to external wall insulation, cavity-wall insulation was associated with poorer mental, respiratory and general health. The authors speculate that the divergent results may be linked to an absence of mechanical ventilation when installing cavity wall insulation (Poortinga et al., 2017).

\subsection{Conclusions and recommendations}

This chapter considered the implications of housing policies to alleviate fuel poverty, through a compressive narrative review of the literatures on the consequences of living in fuel poverty and cold homes, as well as the available evidence on the health and social outcomes of home energy-efficiency improvements. This was expanded by a discussion of a number of recently published studies that have evaluated different housing programmes in Wales, in order to explore whether it makes a difference how they are delivered. The chapter focused on both health and social outcomes to get a complete picture of how such policies improve the lives of those in fuel poverty. The chapter has shown that living in fuel poverty and cold homes has severe implications for people's physical health and their mental and social wellbeing, and that these can be alleviated with well-designed policies. While income support will alleviate financial pressure of those in fuel poverty, there is a dearth of evidence that it provides wider benefits. It is also widely acknowledged that home energy efficiency improvements may be a more sustainable and cost effective way of tackling fuel poverty.

Overall, the evidence of the existing literature is inconclusive but suggestive that affordable warmth and energy-efficiency interventions are beneficial for health (Milner and Wilkinson, 2017). An authoritative systematic review concluded that interventions that target those with inadequate warmth and with pre-existing conditions are more likely to produce health improvements than housing-led neighbourhood renewal and those that target areas rather than individuals in most need (Thomson et al., 2013). The additional evidence from Wales presented in this chapter continues to support some of those conclusions. While an area-based fuel poverty scheme did not produce tangible health benefits in the short and long term (Grey, Jiang, et al., 2017; Poortinga, Rodgers, et al., 2018), a targeted demand-led programme saw immediate reductions in health service utilisation for cardio-vascular and respiratory conditions (Morrison-Rees, 2016). That is not to say that area-based fuel poverty schemes are without merit. In fact, the opposite. The same research has shown that the Arbed programme delivered affordable warmth, alleviate fuel poverty and reduce $\mathrm{CO} 2$ emissions as per its aims, and substantially improved living conditions and wellbeing of households living in low-income areas (ibid). According to one 
resident the improvements helped them to "live in absolute comfort, peace of mind, and economy" and "made the home a proper home rather than a cold house" (Grey, Schmieder-Gaite, et al., 2017).

In contrast to the conclusions of Thomson et al (2013), the additional evidence presented in this chapter suggests that managed housing upgrade programmes cans have substantial positive impacts in terms of residents' health and quality of life. The upgrade programme delivered in Carmarthenshire was linked to reduced emergency hospital admissions (Rodgers, Bailey, Johnson, Berridge, et al., 2018) alongside improved living conditions and household finances (Poortinga et al., 2017). These associations were found for individual measures as well as for the overall investment programme (ibid).

There are still many aspects of the current literature on 'housing and health' that warrant further research. Although the benefits that have already been shown justify interventions in their own right, policy makers may need more evidence to convince them of the value case of widespread energy efficiency investments to tackle fuel poverty and wider social and economic inequalities. There is a clear need for longer follow ups, as most studies so far have had follow ups of less than one year and may as a results have been able to detect health improvements. Indeed, the widespread changes in social and economic conditions that are conducive to better health are suggestive that such improvements will be found in the long term (Poortinga, Rodgers, et al., 2018). Data linkage provides opportunities to evaluate investments retrospectively with routinely collected health utilisation records (cf. Rodgers, Bailey, Johnson, Berridge, et al., 2018). The evidence could be strengthened if policy makers would engage with academics at an early stage so that initiatives can be designed that would facilitate prospective and/or retrospective evaluations. Ideally, an intervention would be carried out using for example a randomised stepped wedge approach (Brown and Lilford, 2006), with a health and economic evaluation component built into any large scale improvement from project conception.

The chapter has also stressed the importance of considering both social and health outcomes, and to combine quantitative and qualitative methods to do justice to fuel poverty as a highly complex social problem. A restricted focus on health outcomes may give the impression that investments in energy efficiency are only justified if they reduce costs to the health services. The findings that energy-efficiency investments improve the lives and well-being of residents, and can help alleviate fuel poverty while saving energy at the same time, provide important lessons for public policy. Even in the absence of tangible health effects, for example for area-based programme, there is compelling case for further investments given the other benefits that have been found. While the 'fabric first' approach to tackle fuel poverty has recently been challenged (Baker, Mould and Restrick, 2018), it still is one of the most effective policies that can be used. That said, it has to be acknowledged that housing is only one factor in the causation of fuel poverty and that it therefore cannot be a panacea for all issues relating to fuel poverty. More research is needed to understand the routes in and out of fuel poverty, and the social conditions that may make householders vulnerable to falling into fuel poverty. This is particularly relevant in the current age of austerity, which has destabilised household incomes while restricting investment in energy efficiency (Middlemiss and Gillard, 2015). Austerity policies may directly counteract the progress that has been made so far and trap vulnerable households in negative feedback loops leading to fuel poverty or worse (Baker, Mould and Restrick, 2018).

(Word count: 6,154) 


\subsection{References}

Age UK (2014) Reducing fuel poverty - a scourge for older people. London: Age UK.

Anderson, W., White, V. and Finney, A. (2012) 'Coping with low incomes and cold homes', Energy Policy, 49, pp. 4052. doi: 10.1016/j.enpol.2012.01.002.

Angelini, V., Daly, M., Moro, M., Navaroo Paniiagua, M., Sidman, E., Walker, I. and Weldon, M. (2018) 'The Winter Fuel Payment, household temperature, and health: A regression discontinuity design study', Public Health Research.

Armstrong, B., Bonnington, O., Chalabi, Z., Davies, M., Doyle, Y., Goodwin, J., Green, J., Hajat, S., Hamilton, I., Hutchinson, E., Mavrogianni, A., Milner, J., Milojevic, A., Picetti, R., Rehill, N., Sarran, C., Shrubsole, C., Symonds, P., Taylor, J. and Wilkinson, P. (2018) 'The impact of home energy efficiency interventions and winter fuel payments on winter- and cold-related mortality and morbidity in England: a natural equipment mixed-methods study', Public Health Research, 6(11).

Baker, K. J., Mould, R. and Restrick, S. (2018) 'Rethink fuel poverty as a complex problem', Nature Energy, 3(8), pp. 610-612. doi: 10.1038/s41560-018-0204-2.

Barnes, M., Butt, S. and Tomaszewski, W. (2010) 'The Dynamics of Bad Housing: The impact of bad housing on the living standards of children', Housing Studies, 26(1), pp. 155-176.

Barton, A., Basham, M., Foy, C., Buckingham, K., Somerville, M., Brazier, J., Roberts, J., Deverill, M., Lawson, K. D., Kearns, A., Petticrew, M., Fenwick, E. a L. and StataCorp (2007) 'The Watcombe Housing Study: the short term effect of improving housing conditions on the health of residents.', Journal of epidemiology and community health, 61(9), pp. 771-777. doi: 10.1136/jech.2006.048462.

Beatty, T. K. M., Blow, L., Crossley, T. F. and O’Dea, C. (2011) 'Cash by any Other Name? Evidence on Labelling from the UK Winter Fuel Payment'. London: Institute of Fiscal Studies.

Boardman, B. (1991) Fuel poverty: from cold homes to affordable warmth. London: Bellhaven Press.

Boardman, B. (2013) Fixing fuel poverty. Challenges and solutions. London: Routledge.

Braubach, M., Heinen, D. and Dame, J. (2008) Preliminary results of the WHO Frankfurt housing intervention project. Copenhagen: World Health Organisation.

Brown, C. A. and Lilford, R. J. (2006) 'The stepped wedge trial design: a systematic review', BMC Medical Research Methodology, 6(1), p. 54. doi: 10.1186/1471-2288-6-54.

Bullen, C., Kearns, R. A., Clinton, J., Laing, P., Mahoney, F. and McDuff, I. (2008) 'Bringing health home: Householder and provider perspectives on the healthy housing programme in Auckland, New Zealand', Social Science $\{\&\}$ Medicine, 66(5), pp. 1185-1196. doi: 10.1016/j.socscimed.2007.11.038.

Cotter, N., Monahan, E., McAvoy, H. and Goodman, P. (2012) 'Coping with the cold - exploring relationships between cold housing, health and social wellbeing in a sample of older people in Ireland', Quality in Ageing and Older Adults. Edited by R. O’Sullivan. Emerald Group Publishing Limited, 13(1), pp. 38-47. doi: 10.1108/14717791211213607.

Crawford, V. L. S. (2003) 'Changes in seasonal deaths from myocardial infarction', QJM, 96(1), pp. 45-52. doi: 10.1093/qjmed/hcg005.

Day, R., Walker, G. and Simcock, N. (2016) 'Conceptualising energy use and energy poverty using a capabilities framework', Energy Policy, 93, pp. 255-264. doi: https://doi.org/10.1016/j.enpol.2016.03.019.

DECC (2015) Cutting the cost of keeping warm. A fuel poverty strategy for England. London: Department of Energy and Climate Change.

Defra \& DTI (2001) The UK Fuel Poverty Strategy. London, United Kingdom: Department for the Environmental Food and Rural Affairs \& Department of Trade and Industry.

Doble, M. (2010) 'A regulatory policy for self-disconnection: An examination of the reasons for and implications of prepayment meter stoppages', Policy Studies, 21(3), pp. 229-243.

Evans, G. W. (2003) 'The built environment and mental health.', Journal of urban health: bulletin of the New York Academy of Medicine, 80(4), pp. 536-555. doi: 10.1093/jurban/jtg063.

Fisk, W. J., Lei-Gomez, Q. and Mendell, M. J. (2007) 'Meta-analyses of the associations of respiratory health effects with dampness and mold in homes', Indoor Air, 17(4), pp. 284-296. doi: 10.1111/j.1600-0668.2007.00475.x.

Frank, D. a, Neault, N. B., Skalicky, A., Cook, J. T., Wilson, J. D., Levenson, S., Meyers, A. F., Heeren, T., Cutts, D. B., Casey, P. H., Black, M. M. and Berkowitz, C. (2006) 'Heat or eat: the Low Income Home Energy Assistance Program and nutritional and health risks among children less than 3 years of age.', Pediatrics, 118(5), pp. e1293--302. doi: 10.1542/peds.2005-2943.

Gilbertson, J., Grimsley, M. and Green, G. (2012) 'Psychosocial routes from housing investment to health: Evidence from England's home energy efficiency scheme', Energy Policy. Elsevier, 49, pp. 122-133. doi: 10.1016/j.enpol.2012.01.053. Gilbertson, J., Stevens, M., Stiell, B. and Thorogood, N. (2006) 'Home is where the hearth is: Grant recipients' views of England's Home Energy Efficiency Scheme (Warm Front)', Social Science and Medicine, 63(4), pp. 946-956. doi: 10.1016/j.socscimed.2006.02.021.

Green, G. and Gilbertson, J. (2008a) 'Evaluation of Warm Front Scheme'. Jake Abbas, Deputy Director, ja18@york.ac.uk. 
Green, G. and Gilbertson, J. (2008b) Warm Front Better Health - Health Impact Evaluation of the Warm Front Scheme. Sheffield: Sheffield Hallam University. Available at: http://www.shu.ac.uk/research/cresr/sites/shu.ac.uk/files/warmfront-health-impact-eval.pdf.

Grey, C., Jiang, S., Nascimento, C., Rodgers, S. E. E., Johnson, R., Lyons, R. A. A. and Poortinga, W. (2017) 'The shortterm health and psychosocial impacts of domestic energy efficiency investments in low-income areas: a controlled before and after study', BMC Public Health, 17(1), pp. 1-10. doi: 10.1186/s12889-017-4075-4.

Grey, C., Schmieder-Gaite, T., Jiang, S., Nascimento, C. and Poortinga, W. (2017) 'Cold homes, fuel poverty and energy efficiency improvements: a longitudinal focus group approach’, Indoor and Built Environment, 26(7), pp. 902-913. doi: $10.1177 / 1420326 \times 17703450$.

Gunnbjörnsdóttir, M. I., Franklin, K. A., Norbäck, D., Björnsson, E., Gislason, D., Lindberg, E., Svanes, C., Omenaas, E., Norrman, E., Jõgi, R., Jensen, E. J., Dahlman-Höglund, A. and Janson, C. (2006) 'Prevalence and incidence of respiratory symptoms in relation to indoor dampness: the RHINE study.', Thorax, 61(3), pp. 221-5. doi: 10.1136/thx.2005.057430.

Harrington, B. E., Heyman, B., Merleau-Ponty, N., Stockton, H., Ritchie, N. and Heyman, A. (2005) 'Keeping warm and staying well: findings from the qualitative arm of the Warm Homes Project.', Health and Social Care in the Community, 13(3), pp. 259-267. doi: 10.1111/j.1365-2524.2005.00558.x.

Harris, J., Hall, J., Meltzer, H., Jenkins, R., Oreszczyn, T. and McManus, S. (2010) Health, mental health and housing conditions in England. London: National Centre for Social Research and Eaga.

Hills, J. (2012) Getting the measure of fuel poverty. London: Department of Energy and Climate Change.

Hong, S. H., Gilbertson, J., Oreszczyn, T., Green, G. and Ridley, I. (2009) 'A field study of thermal comfort in lowincome dwellings in England before and after energy efficient refurbishment', Building and Environment, 44(6), pp. 1228-1236. doi: 10.1016/j.buildenv.2008.09.003.

Howden-Chapman, P., Matheson, A., Crane, J., Viggers, H., Cunningham, M., Blakely, T., Cunningham, C., Woodward, A., Saville-Smith, K., O’Dea, D., Kennedy, M., Baker, M., Waipara, N., Chapman, R. and Davie, G. (2007) 'Effect of insulating existing houses on health inequality: cluster randomised study in the community.', BMJ (Clinical research ed.), 334(7591), p. 460. doi: 10.1136/bmj.39070.573032.80.

Howden-Chapman, P., Pierse, N., Nicholls, S., Gillespie-Bennett, J., Viggers, H., Cunningham, M., Phipps, R., Boulic, M., Fjällström, P., Free, S., Chapman, R., Lloyd, B., Wickens, K., Shields, D., Baker, M., Cunningham, C., Woodward, A., Bullen, C. and Crane, J. (2008) 'Effects of improved home heating on asthma in community dwelling children: randomised controlled trial.', BMJ (Clinical research ed.), 337, p. a1411. doi: 10.1136/bmj.a1411.

Howieson, S. G. (2005) 'Multiple deprivation and excess winter deaths in Scotland', The Journal of the Royal Society for the Promotion of Health, 125(1), pp. 18-22. doi: 10.1177/146642400512500110.

Iparraguirre, J. (2015) 'Have winter fuel payments reduced excess winter mortality in England and Wales?', pp. 26-33. Available at: https://doi.org/10.1093/pubmed/fdu063.

Jevons, R., Carmichael, C., Crossley, A. and Bone, A. (2016) 'Minimum indoor temperature threshold recommendations for English homes in winter - A systematic review.', Public health, 136, pp. 4-12. doi: 10.1016/j.puhe.2016.02.007.

Kwak, K. (2003) 'Adolescents and Their Parents: A Review of Intergenerational Family Relations for Immigrant and Non-Immigrant Families', Human Development. Karger Publishers, 46(2-3), pp. 115-136. doi: 10.1159/000068581.

Liddell, C. and Guiney, C. (2015) 'Living in a cold and damp home: Frameworks for understanding impacts on mental well-being', Public Health, 129(3), pp. 191-199. doi: 10.1016/j.puhe.2014.11.007.

Liddell, C. and Morris, C. (2010) 'Fuel poverty and human health: A review of recent evidence', Energy Policy, 38(6), pp. 2987-2997. doi: 10.1016/j.enpol.2010.01.037.

Marmot Review Team, Marmot, M., Geddes, I., Bloomer, E., Allen, J., Goldblatt, P., Marmot Review Team and Team, M. R. (2011) The health impacts of cold homes and fuel poverty. London: Friends of the Earth \& the Marmot Review Team. doi: 10.1136/bmj.d2807.

Middlemiss, L. and Gillard, R. (2015) 'Fuel poverty from the bottom-up: Characterising household energy vulnerability through the lived experience of the fuel poor', Energy Research and Social Science. Elsevier Ltd, 6, pp. 146-154. doi: 10.1016/j.erss.2015.02.001.

Milner, J. and Wilkinson, P. (2017) 'Commentary: Effects of Home Energy Efficiency and Heating Interventions on Cold-related Health’, Epidemiology, 28(1), pp. 86-89. doi: 10.1097/EDE.0000000000000570.

Moore, R. (2012) 'Definitions of fuel poverty: Implications for policy', Energy Policy. Elsevier, 49, pp. 19-26. doi: 10.1016/j.enpol.2012.01.057.

Morrison-Rees, S. (2016) The fuel poverty data linking project. Emerging findings report. Cardiff: Welsh Government, Knowledge and Analytical Services.

Nicol, S., Roys, M., Ormandy, D. and Ezratty, V. (2016) The cost of poor housing in the European Union. Edited by Building Research Establishment. Watford.

ONS (2016) 'Excess Winter Mortality in England and Wales: 2015/16 (Provisional) and 2014/15 (Final). Increased Deaths During Winter Months by Sex, Age, Region and Cause, Including Figures on Temperature and Influenza'. Newport: Office for National Statistics.

Oreszczyn, T., Hong, S. H., Ridley, I. and Wilkinson, P. (2006) 'Determinants of winter indoor temperatures in low income households in England', Energy and Buildings, 38(3), pp. 245-252. doi: 10.1016/j.enbuild.2005.06.006. 
Petticrew, M., Rehfuess, E., Noyes, J., Higgins, J. P. T., Mayhew, A., Pantoja, T., Shemilt, I. and Sowden, A. (2013) 'Synthesizing evidence on complex interventions: how meta-analytical, qualitative, and mixed-method approaches can contribute', Journal of Clinical Epidemiology, 66(11), pp. 1230-1243. doi: https://doi.org/10.1016/j.jclinepi.2013.06.005. Platt, S., Mitchell, R., Walker, R., Hopton, J., Petticrew, M., Corbett, J., Hope, S., Martin, C. and Walker, J. (2007) The Scottish Executive Central Heating Programme: Assessing Impacts on Health. Summary. Edinburgh: Scottish Executive Social Research. Available at: http://healthincontext.com/reports/Heat\%7B_\%7DReport.pdf.

Poortinga, W., Jiang, S., Grey, C. and Tweed, C. (2018) 'Impacts of energy-efficiency investments on internal conditions in low-income households', Building Research and Information. Taylor \& Francis (Routledge): STM, Behavioural Science and Public Health Titles, 46, pp. 653-667. doi: 10.1080/09613218.2017.1314641.

Poortinga, W., Jones, N., Lannon, S. and Jenkins, H. (2017) 'Social and health outcomes following upgrades to a national housing standard: A multilevel analysis of a five-wave repeated cross-sectional survey', BMC Public Health, 17(1). doi: 10.1186/s12889-017-4928-x.

Poortinga, W., Rodgers, S. E., Lyons, R. A., Anderson, P., Tweed, C., Grey, C. N. B., Jiang, S., Johnson, R. D., Watkins, A. and Winfield, T. G. (2018) 'The health impacts of energy performance investments in low-income areas: a mixedmethods approach', Public Health Research, 6(5). doi: 10.3310/phr06050.

Public Health England (2014) Minimum home temperature thresholds for health in winter: a systematic literature review. London: Public Health England.

Rodgers, S. E., Bailey, R., Johnson, R., Berridge, D., Poortinga, W., Lannon, S., Smith, R. and Lyons, R. A. (2018) 'Emergency hospital admissions associated with a non-randomised housing intervention meeting national housing quality standards: a longitudinal data linkage study', Journal of Epidemiology and Community Health. BMJ Publishing Group, 72(10). Available at: http://orca.cf.ac.uk/113180/.

Rodgers, S. E., Bailey, R., Johnson, R., Poortinga, W., Smith, R., Berridge, D., Anderson, P., Phillips, C., Lannon, S., Jones, N., Dunstan, F. D., Morgan, J., Evans, S. Y., Every, P., Lyons, R. A., Anserson, P., Phillips, C., Lannon, S., Jones, N., Dunstan, F. D., Morgan, J., Evans, S. Y., Every, P. and Lyons, R. A. (2018) 'Health impact, and economic value, of meeting housing quality standards: a retrospective longitudinal data linkage study', Public Health Research. NIHR Health Technology Assessment Programme, 6(8). doi: 10.3310/phr06080.

Scottish Government (2018) Fuel poverty strategy for Scotland 2018. Edinburgh: Scottish Government.

Shenassa, E. D., Daskalakis, C., Liebhaber, A., Braubach, M. and Brown, M. (2007) 'Dampness and mold in the home and depression: An examination of mold-related illness and perceived control of one's home as possible depression pathways', American Journal of Public Health, 97(10), pp. 1893-1899. doi: 10.2105/AJPH.2006.093773.

Shortt, N. and Rugkåsa, J. (2007) “"The walls were so damp and cold” fuel poverty and ill health in Northern Ireland: Results from a housing intervention', Health and Place, 13(1), pp. 99-110. doi: 10.1016/j.healthplace.2005.10.004.

Simcock, N., Walker, G. and Day, R. (2016) 'Fuel poverty in the UK: beyond heating?', People, Place and Policy, 10(1), pp. $25-41$.

Snell, C., Bevan, M. and Thomson, H. (2015) 'Justice, fuel poverty and disabled people in England', Energy Research \& Social Science, 10, pp. 123-132. doi: https://doi.org/10.1016/j.erss.2015.07.012.

Somerville, M., Mackenzie, I., Owen, P. and Miles, D. (2000) 'Housing and health: does installing heating in their homes improve the health of children with asthma?', Public health, 114(6), pp. 434-439. doi: 10.1038/sj.ph.1900687.

Sunderland, L. and Croft, D. (2011) 'Energy poverty - risks, conflicts and opportunities in the development of energy poverty alleviation policy under the umbrella of energy efficiency and climate change', in ECEEE Summer Study 2011 Proceedings. Belambra Presqu'île de Giens, FranceWeb site versionEnergy efficiency first: The foundation of a lowcarbon societyConference proceedingseceee 2011 Summer Study: ECEEE, pp. 461-472.

Thomson, H. and Snell, C. (2013) 'Quantifying the prevalence of fuel poverty across the European Union', Energy Policy, 52, pp. 563-572. doi: https://doi.org/10.1016/j.enpol.2012.10.009.

Thomson, H. and Thomas, S. (2015) 'Developing empirically supported theories of change for housing investment and health', Social Science and Medicine, 124, pp. 205-214. doi: 10.1016/j.socscimed.2014.11.043.

Thomson, H., Thomas, S., Sellstrom, E. and Petticrew, M. (2013) 'Housing improvements for health and associated socioeconomic outcomes.', The Cochrane Database of Systematic Reviews, 2(3), p. CD008657. doi: 10.1002/14651858.CD008657.pub2.

Wells, S., Graham, K., Speechley, M. and Koval, J. J. (2005) 'Drinking patterns, drinking contexts and alcohol-related aggression among late adolescent and young adult drinkers.', Addiction (Abingdon, England), 100(7), pp. 933-944. doi: 10.1111/j.1360-0443.2005.001121.x.

Welsh Assembly Government (2008) The Welsh Housing Quality Standard. Revised guidance for social landlords on Interpretation and achievement of the Welsh Housing Quality Standard. Cardiff: Welsh Assembly Government. Available at: http://gov.wales/docs/desh/publications/141030-whqs-guide-for-social-landlords-en.pdf.

Welsh Assembly Government (2010) Fuel Poverty Strategy. Cardiff, Wales: Welsh Government.

Welsh Government (2017) The Fuel Poverty Data Linking Project Findings Report No.1: Initial Findings on the Impact on Health of the Warm Homes Nest Scheme. 17/2017. Cardiff: Welsh Government, Government Social Research.

Wilkinson, P., Landon, M., Armstrong, B., Stevenson, S., Pattenden, S., Mckee, M. and Fletcher, T. (2001) Cold comfort. The social and environmental determinants of excess winter deaths in England, 1986-96. Bristol: The Policy Press and the Joseph Rowntree Foundation. 
Willand, N., Ridley, I. and Maller, C. (2015) 'Towards explaining the health impacts of residential energy efficiency interventions - A realist review. Part 1: Pathways', Social Science and Medicine, 133, pp. 191-201. doi: 10.1016/j.socscimed.2015.02.005.

Woodfine, L., Neal, R. D., Bruce, N., Edwards, R. T., Linck, P., Mullock, L., Nelhans, N., Pasterfield, D., Russell, D. and Russell, I. (2011) 'Enhancing ventilation in homes of children with asthma: Pragmatic randomised controlled trial', British Journal of General Practice, 61(592), pp. 724-732. doi: 10.3399/bjgp11X606636.

Woodhouse, P. R., Khaw, K. T. and Plummer, M. (1993) 'Seasonal variation of blood pressure and its relationship to ambient temperature in an elderly population.', Journal of hypertension, 11(11), pp. 1267-1274.

World Health Organization (1985) 'Health Impact of Low Indoor Temperatures: Report on a WHO meeting'. Available at: http://www.theclaymoreproject.com/uploads/associate/365/file/Health (Accessed: 12 June 2016). 
Table 1: Methodologies used to evaluate the Arbed, Nest and WHQS programmes

\begin{tabular}{|l|c|c|c|}
\hline & Arbed & Nest & WHQS $^{(\mathbf{1})}$ \\
\hline Community-based & $\checkmark^{(\mathrm{a})}$ & & $\checkmark^{(\mathrm{f})}$ \\
\hline Focus groups & $\checkmark^{(\mathrm{b})}$ & & \\
\hline Household monitoring & $\checkmark^{(\mathrm{c})}$ & & \\
\hline Data Linkage & $\checkmark^{(\mathrm{d})}$ & $\checkmark^{(\mathrm{e})}$ & $\checkmark^{(\mathrm{g})}$ \\
\hline
\end{tabular}

Note: ${ }^{(1)}$ Welsh Housing Quality Standard; ${ }^{(a)}$ Grey, Schmieder-Gaite, et al. (2017); ${ }^{(b)}$ Grey, Jiang et al. (2017); (c) Poortinga et al. (2018); ${ }^{(d)}$ Poortinga, Rodgers, et al. (2018); (e) Morrison-Rees (2016); (f) Poortinga et al (2017); ${ }^{(g)}$ Rodgers et al. 2018. 


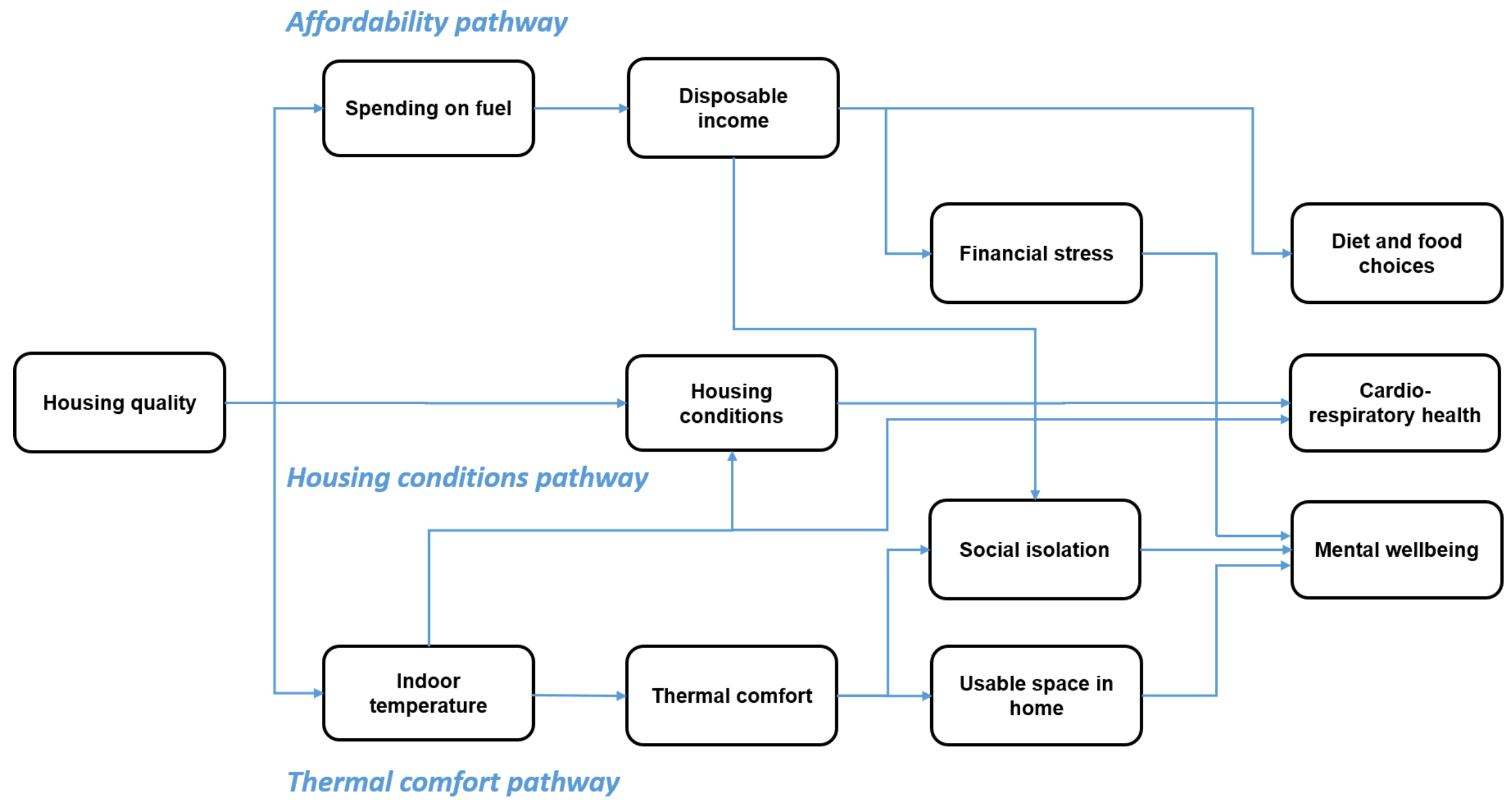

Figure : Conceptual model of pathways linking housing quality to health and social outcomes 